\title{
The Electrochemical Behaviour of PEDOT Film Electrosynthesized in Presence of Some Dopants
}

\author{
Florina Branzoi ${ }^{1}$, Viorel Branzoi ${ }^{2}$ \\ ${ }^{1}$ Institute of Physical Chemistry "Ilie Murgulescu", Bucharest, Romania \\ ${ }^{2}$ University Politehnica of Bucharest, Bucharest, Romania \\ Email: fbrinzoi@chimfiz.icf.ro
}

Received 22 June 2015; accepted 27 September 2015; published 30 September 2015

Copyright (C) 2015 by authors and Scientific Research Publishing Inc.

This work is licensed under the Creative Commons Attribution International License (CC BY). http://creativecommons.org/licenses/by/4.0/

(c) (i) Open Access

\begin{abstract}
Electropolymerization and characterization of poly(3,4-ethylene dioxythiophene) (PEDOT) doped with functionalized single-walled carbon nanotubes (SWANTs) polyaminobenzene sulfonic acid (PABS) and different dopants were studied. It was fabricated by a simple oxidative electropolymerization method. The nanocomposite coatings have been prepared by using electrochemical methods from aqueous solutions, such that the components were deposited onto platinum electrode substrate. The morphology of composite films was analyzed by scanning electron microscopy (SEM). The electrochemical and physical properties of the resulting composites were evaluated by cyclic voltammetry (CV), electrochemical impedance spectroscopy (EIS) and Fourier transform infrared spectroscopy (FT-IR) techniques in $0.1 \mathrm{M} \mathrm{LiClO}_{4}$ aqueous solutions. The value of specific electrochemical capacitance of the composite films is considerably higher than that of the pure polymers films. The improved properties of the electrodes were obtained by using these composite films. The dopant substances used were sodium dodecyl sulfate (SDS) and 1,2-Dihydroxy-benzene-3,5-disulfonic acid disodium salt hydrate (tiron).
\end{abstract}

\section{Keywords}

Nanocomposite Films, Carbon Nanotubes, Electropolymerization, SEM, EIS, Capacitance

\section{Introduction}

Conducting polymers are also intriguing molecular structures because of their ability to dramatically change properties when stimulated by an electric signal. These materials offer exciting prospects for a wide range of 
new devices such as membranes, artificial muscles, solar cells, batteries, capacitors, corrosion protection coatings or sensor applications [1]-[5].

Carbon nanotubes (CNTs), as one of the most interesting carbon materials, have attracted an enormous interest over the recent years, as a result of their unique properties and a broad range of potential applications. Their very high mechanical resilience, high electrical conductivity, chemical and mechanical properties and large surface areas are particularly relevant for diverse applications such as in nanoelectronics, biosensors, supercapacitors and so on [3]-[7].

Recently, conducting polymers/carbon nanotubes composites have received significant interest because the incorporation of carbon nanotubes into conducting polymers can lead to new composite materials possessing the properties of each component with a synergistic effect that would be useful in particular applications [8]-[13].

Composite materials based on the coupling of conducting organic polymers (CPs) and CNTs have shown that they possess properties of the individual components with a synergistic effect [14]. In this context, a special attention has been paid to the following CPs: polyaniline (PANI), polypyrrole (PPY), polythiophene (PTh) [15][21]. Among the numerous materials devised, development of the polythiophene derivative, polyethylene-dioxythiophene (PEDOT), has shown significant promise for the challenge at hand. Poly(3,4-ethylenedioxy-thiophene) (PEDOT) is one of the most successful polythiophene derivatives because of its interesting properties: high conductivity, unusual electroactivity and relative environmental stability [22]-[26]. PEDOT proved better aqueous stability and biocompatibility than polypyrrole and polyaniline and therefore it is considered a promising polymer appropriate for continuous sensing and even in vivo implantation [27]-[29]. It can be produced electrochemically in a variety of solvents. It has been showed that the electrochemical and physical properties of polymers are greatly influenced by the nature of dopant and electrolyte during the polymeric process [30]-[34].

The combination of CNTs with CPs offers an attractive route to reinforce the polymer as well as to introduce electronic properties based on morphological modification or electronic interaction between the two components [10]-[13] [18]-[26]. However, it is difficult to process CNTs and insoluble in most solvents. In order to broaden their applications it is necessary to tailor their solubility properties. For this cause, in this study SWCNTs-single-walled carbon nanotubes covalently functionalized with polyaminobenzene sulfonic acid were used. The SWCNTs graft copolymer has excellent solubility in water and some organic solvents and it also exhibits an order of magnitude increase in electrical conductivity. It was also demonstrated that SWCNTs-PABS (single walled carbon nanotubes functionalized with polyaminobenzene sulfonic acid) showed an improved sensor performance compared to unfunctionalized SWCNTs, because polyaminobenzene sulfonic acid is a conductive organic compound in its own right. Additionally, the presence of numerous functional groups in SWCNTs-PABS means that there is potential for covalent immobilization of various big molecules, especially biomolecules.

This study is a continuation of previous work on the synthesis and analysis of the composite films doped with some functionalized single-walled carbon nanotubes that have been deposited on the platinum substrate by electrochemical polarization method.

In this study the electrochemical synthesis of nanocomposite films from conducting polymers-poly(3,4-ethylene dioxythiophene) and functionalized single-walled carbon nanotubes with polyaminobenzene sulfonic acid (PEDOT-FSWCNTs) and different dopants (sodium dodecyl sulfate and 1,2-Dihydroxy-benzene-3,5-disulfonic acid disodium salt hydrate) is described. The electrochemical characterization of these nanocomposites was by cyclic voltammetry, electrochemical impedance spectroscopy, and the surface morphology analysis was by scanning electron microscopy (SEM) and Fourier transform infrared spectroscopy (FT-IR) techniques.

\section{Experimental}

The electrochemical synthesis and measurements were carried out by using a single-compartment cell with the conventional three electrode set up at room temperature. The cell was connected to a VoltaLab potentiostat coupled to a PC running Voltamaster software. A saturated calomel electrode (SCE) was employed as the reference electrode and a platinum gauze as an auxiliary electrode. The working electrode was a platinum disk with a surface area $0.5 \mathrm{~cm}^{2}$. All chemicals were reagent grade and used as received without further purification. In this paper were used 3,4-ethylenedioxy thiophene (EDOT) (99.5\% Aldrich), $\mathrm{LiClO}_{4}$ (Merck), sodium dodecyl sulfate (SDS) (98\% Fluka), tiron (Fluka) and single-walled carbon nanotubes functionalized with polyaminobenzene sulfonic acid (FSWCNTs) were the commercial product from Sigma-Aldrich with the following character- 
istics: $80 \%-90 \%$ carbon basis, $\mathrm{D} \times \mathrm{L} 2-10 \mathrm{~nm} \times 0.5-2 \mu \mathrm{m}$, bundle dimensions. All the solutions were prepared with double distilled water.

\subsection{Preparation of Modified Electrode}

Before each electrochemical measurement the surface of the working electrode was mechanically polished with 0.3 and $0.05 \mu \mathrm{m}$ alumina powders and rinsed in double distilled water and ethanol. The prepared electrodes were dried and used for modification.

Nanocomposite films of CPs/FSWCNTs have been prepared by electrochemical polymerization from a solution containing the functionalized carbon nanotubes (FSWCNTs) and the corresponding monomer (PEDOT). FSWCNTs were used in this paper namely: single wall carbon nanotubes (SWCNTs) functionalized with polyaminobenzene sulfonic acid (see Scheme 1).

In first stage consisted of preparing the FSWCNTs aqueous suspension $(10 \mathrm{mg} / \mathrm{L})$ by using sonication $(1$ hour). Furthermore, the synthesis solution was obtained by dissolving the monomer and the corresponding supporting electrolyte in the FSWCNTs aqueous suspension. The behavior of the negatively charged FSWCNTs in solution was that of the only supporting electrolyte and dopant for the PEDOT depositions. Therefore, during the electropolymerization process, the FSWCNTs are encased in polymers in the form of counter ions or dopants.

Thus, PEDOT/SWCNTs composite films were obtained from an aqueous solution containing $0.025 \mathrm{~mol} / \mathrm{L}$ of 2,3-dioxythiophene $+0.1 \mathrm{M}$ of $\mathrm{LiClO}_{4}+10 \mathrm{mg} / \mathrm{L}$ of FSWCNTs by cyclic voltammetry in the potential scanning range of $0 \mathrm{mV}$ to $+1250 \mathrm{mV}$ at a scan rate of $10 \mathrm{mV} / \mathrm{s}$ and for a cycles number of 20 .

\subsection{Characterization of the Modified Electrodes}

The electrochemical properties of the composite films were evaluated by cyclic voltammetry (CV), electrochemical impedance spectroscopy (EIS), Fourier transform infrared spectroscopy (FT-IR) and scanning electron microscopy (SEM). The electrochemical characterization of the PEDOT/FSWCNTs was carried out in $0.1 \mathrm{M}$ $\mathrm{LiClO}_{4}$ cycling aqueous solutions for comparison and because the dopant anion of the polymeric films is the same with the anion of the cycling solution. Twenty consecutive potential scans were performed for modified electrodes and they were cycled in the potential range of $0 \mathrm{mV}$ to $+1250 \mathrm{mV}$ with a scan rate of $50 \mathrm{mV} / \mathrm{s}$. The impedance measurements were carried using a VoltaLab 40 potentiostat/galvanostat in the frequency range of $100 \mathrm{kHz}$ to $1 \mathrm{mHz}$ with an AC wave of $5 \mathrm{mV}$ (peak-to-peak) overlaid on a DC bias potential and the impedance data were obtained at a rate of 10 points per decade change in frequency.

\section{Results and Discussions}

In the first stage, the PEDOT/Pt coating has been also electrodeposited onto electrode surface (platinum) by electrochemical polymerization from an aqueous solutions containing $0.025 \mathrm{~mol} / \mathrm{L}$ 2,3-dioxythiophene and 0.1 $\mathrm{M} \mathrm{LiClO}_{4}$ as supporting electrolyte (see Figure 1 inset). The obtained the PEDOT/Pt film was presented in previous work.

Composite films of poly(3,4-ethylenedioxythiophene) and functionalized, single-walled carbon nanotubes with polyaminobenzene sulfonic acid (PEDOT-SWCNTs/PABS) were fabricated by a simple oxidative electropolymerization method. These films were electrodeposited on a platinum working electrode using a classical system with three electrodes.

The PEDOT/SWCNTs-polyaminobenzene sulfonic acid film was obtained on the platinum substrate in a

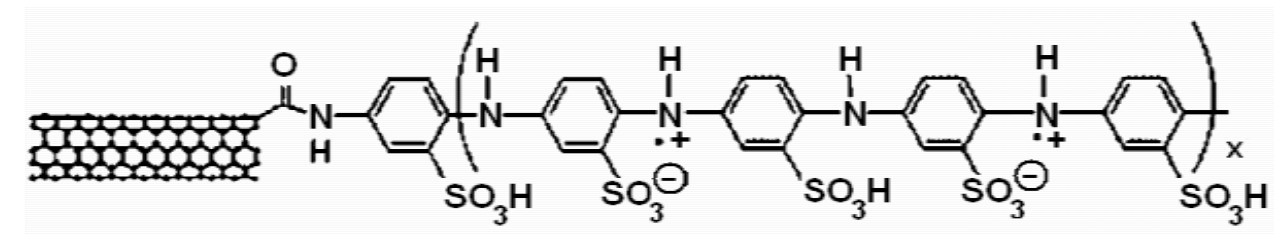

Scheme 1. Chemical structure of single walled carbon nanotube functionalized with polyaminobenzene sulfonic acid (SWCNTs-PABS). 
synthesis solution of $0.025 \mathrm{~mol} / \mathrm{L}$ 2,3-dioxythiophene $+10 \mathrm{mg} / \mathrm{L}$ carbon nanotubes polyaminobenzene sulfonic acid. The obtained cyclovoltammograms are given in Figure 1 and have the same shapes with those obtained for PEDOT/Pt modified electrode cycled in the same conditions, but in this case the anodic peaks are much higher than those for PEDOT film. The current is increasing upon continuous cycling, being indicative for a conductive film formation. This fact can be explained taking into account that, FSWCNTs (in our case SWCNTs-PABS) are negatively charged and they can act as doped anions and consequently, the conductivity of PEDOT/FSWCNTs composite film increases.

The PEDOT/SWCNTs-PABS composites presents higher currents $\left(7.62 \mathrm{~mA} / \mathrm{cm}^{2}\right)$ than PEDOT films (4.96 $\mathrm{mA} / \mathrm{cm}^{2}$ ), which translates into larger capacitance. Also, the PEDOT/FSWCNTs having more a poros structure for ion transportand a higher and potential-independent electronic conductivity through the adsorbed SWCNTs film, can explain the difference in current between PEDOT and PEDOT/FSWCNTs. The presented facts indicate a faster kinetics in the composite, which can be attributed to the higher electronic conductivity of the FSWCNTs network. Therefore the redox processes that take place in nanocomposite film are more complex and more intense than the ones in the pure PEDOT film.

The PEDOT/ SWCNTs-PABS/dopant films were obtained on the platinum substrate in a synthesis solution of $0.025 \mathrm{~mol} / \mathrm{L}$ 2,3-dioxythiophene $+10 \mathrm{mg} / \mathrm{L}$ SWCNTs-PABS $+0.01 \mathrm{~mol} / \mathrm{L}$ dopant substance in $0.1 \mathrm{M} \mathrm{LiClO}_{4}$ by cyclic voltammetry in the scanning potential range of 0 to $+1250 \mathrm{mV}$ at a scan rate of $10 \mathrm{mV} / \mathrm{s}$ and for 10 cycles. The dopant substances used were SDS (Sodium dodecyl sulfate) and tiron (1,2-Dihydroxybenzene-3,5-disul-fonic acid disodium salt hydrate).

In the presence of dopant (SDS and tiron, see Figure 2 and Figure 3), it is observed that the current response of doped PEDOT films increases with addition of the dopant. Moreover, the current increases with continuous cycling in the potential range as seen in Figure 2 and Figure 3. The comparison of repetitive cyclic voltammograms of PEDOT and PEDOT/SWCNTs-PABS/dopant composite film, respectively, clearly showed differences. furthermore, the current intensities are lower in case of pure PEDOT than with respect to nanocomposite/dopant and they decrease upon continuous cycling as it can be seen from voltammograms in Figure 2 and Figure 3. During the first potential scan, the polymerization potential of PEDOT/SWCNTs-PABS/dopant on Pt is around $1.05 \mathrm{~V}$, while the onset of polymerization shifts significantly on following scans to more positive potentials and stabilizes at $1.15 \mathrm{~V}$. The choice of the electrochemical synthesis method has an influence on the morphology, appearance and adhesion of the polymer. Generally, all PEDOT composite films obtained by alternating polarization were uniform, smooth and adherent to the surface of Pt electrode than the ones obtained at constant current or potential.

The electrochemical behaviour of the PEDOT, PEDOT/SWCNTs-PABS films deposited electrochemically from aqueous solution in the absence and presence of dopant (SDS and tiron) was characterized further using cyclic voltammetry. The electrochemical characteristics of obtained PEDOT/Pt film was study in the cycling solutions, an aqueous solution of $0.1 \mathrm{M} \mathrm{LiClO}_{4}$ (see Figure 4 inset) and it was presented in previous work.

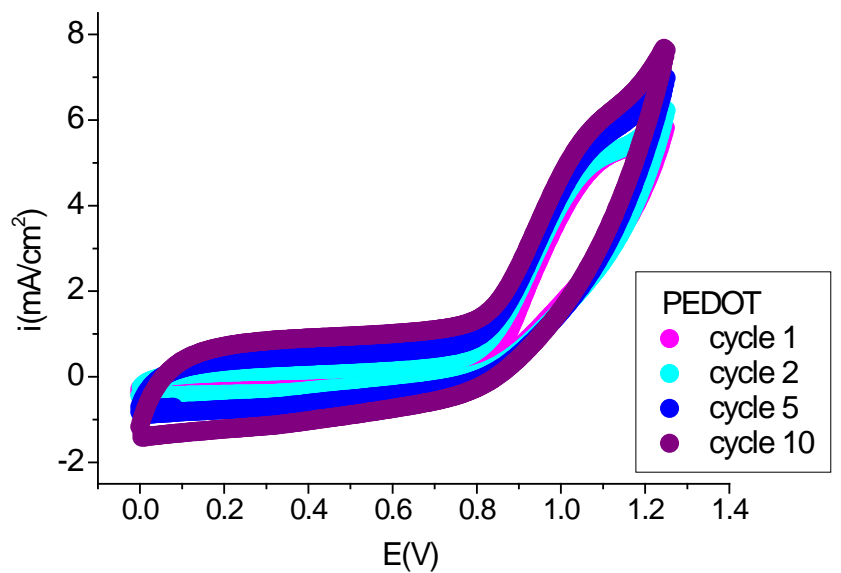

(a)

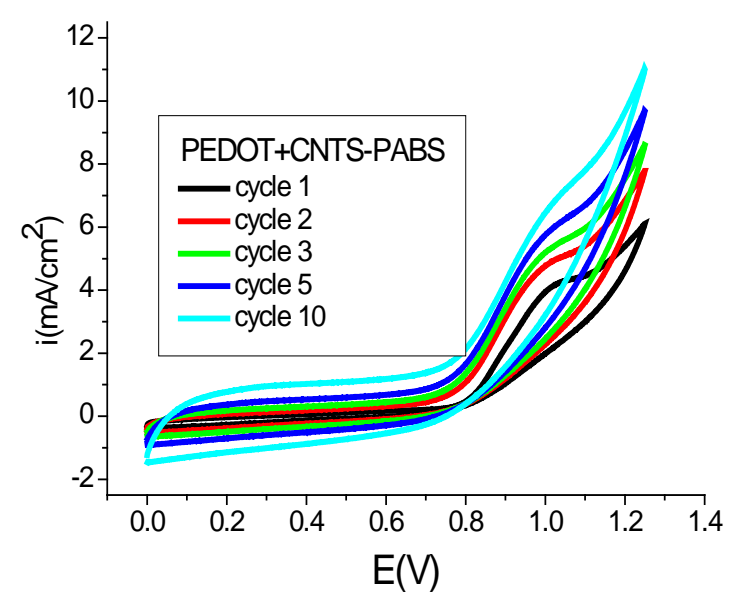

(b)

Figure 1. Polymerization cyclovoltammograms of 2,3-dioxythiophene + SWCNTs-PABS in $0.1 \mathrm{M} \mathrm{LiClO}_{4}$ aqueous solution. Inset electropolymerization PEDOT/Pt. 


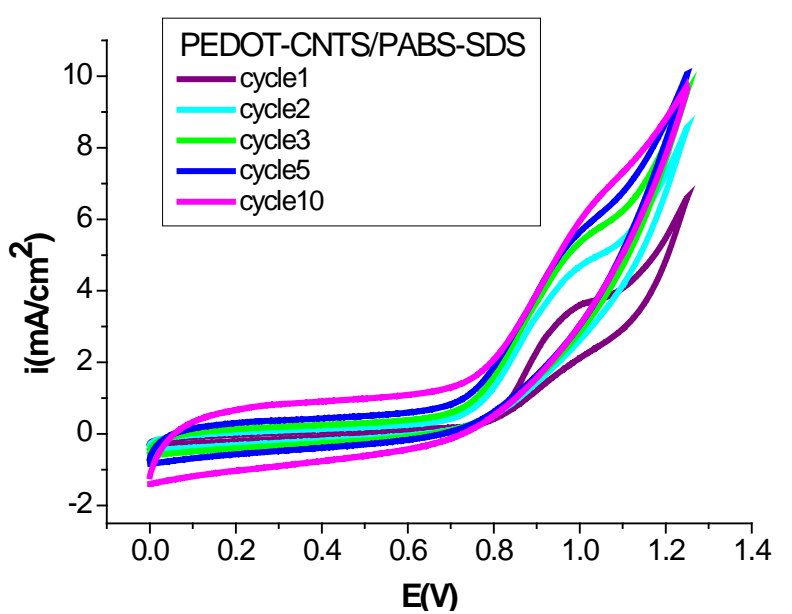

(a)

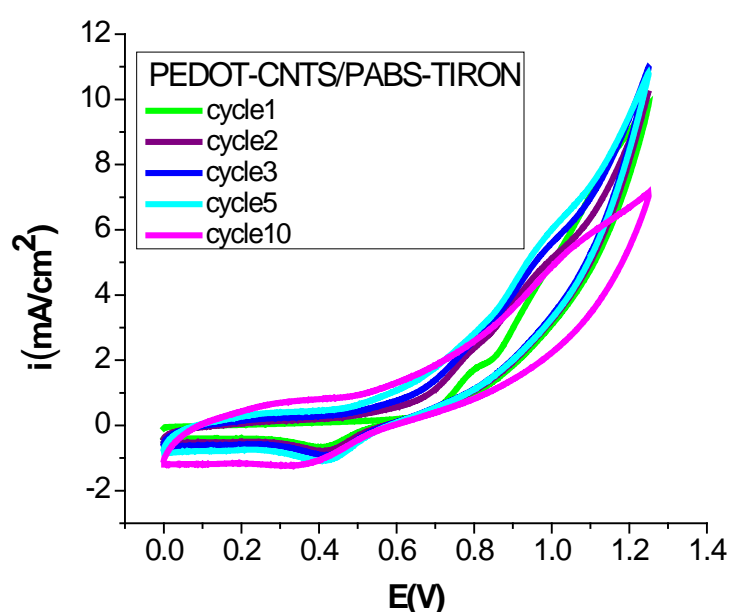

(b)

Figure 2. Polymerization cyclovoltammograms of (a) PEDOT/SWCNTs-PABS/SDS and (b) PEDOT/CNT-PABS/tiron in $0.1 \mathrm{M} \mathrm{LiClO}_{4}$ aqueous solution.

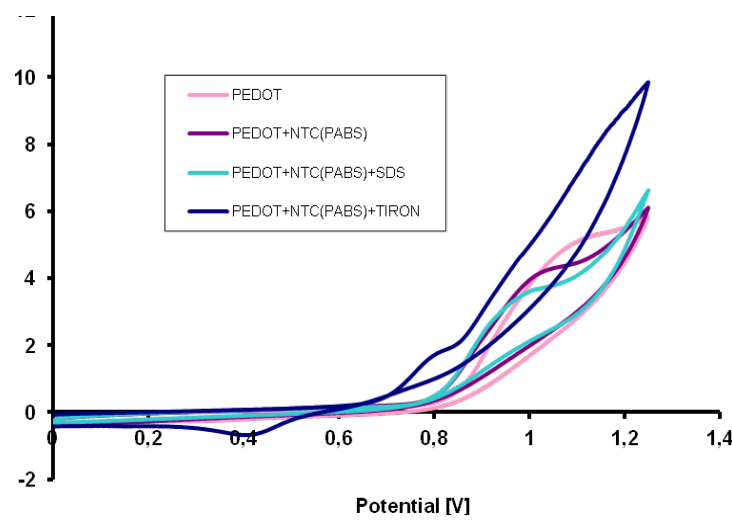

(a)

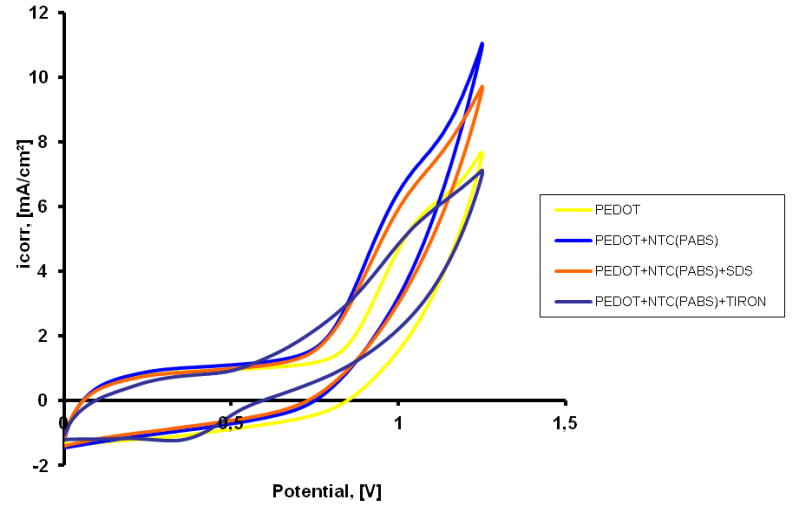

(b)

Figure 3. Comparative polymerization cyclovoltammograms of PEDOT + SWCNTs-PABS + dopant in $0.1 \mathrm{M} \mathrm{LiClO}_{4}$ aqueous solution, $1^{\text {st }}$ Cycle (a) and $10^{\text {th }}$ Cycle (b).

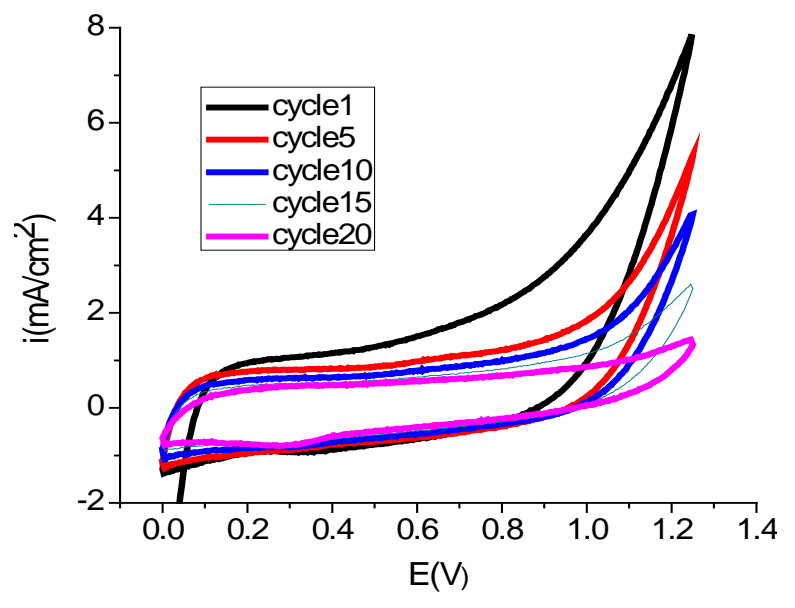

(a)

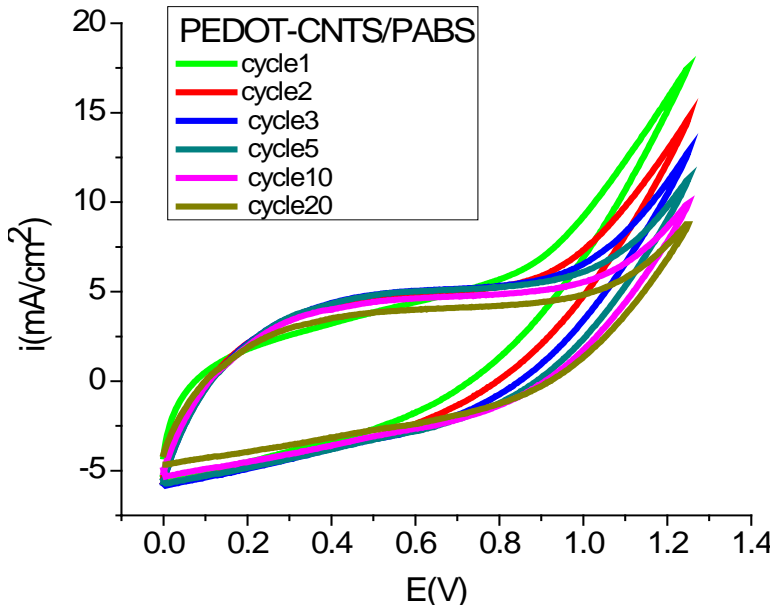

(b)

Figure 4. Cyclic voltammograms of PEDOT/SWCNTs-PABS film in cycling solution (monomer free) of $0.1 \mathrm{M} \mathrm{LiClO}_{4}$. Inset PEDOT/Pt film. 
Figure 4 reports the cyclic voltammograms of PEDOT/CNT-PABS recorded in aqueous solution of $0.1 \mathrm{M}$ $\mathrm{LiClO}_{4}$ in wide potential range to explore all possible electrochemical properties of this film in aqueous electrolyte. The modified electrode type PEDOT/CNT-PABS/Pt was cycled on the potential range from 0 up to 1250 $\mathrm{mV}$ with a sweep rate of $50 \mathrm{mV} / \mathrm{s}$ and for a cycles number of 20, see Figure 4. These films can be cycled repeatedly between the conducting (oxidized) and insulating (neutral) state without significant decomposition of the material, which is consistent with the results reported in the literature [35]. For the cyclic voltammograms to exhibit better capacitive features (e.g. a rectangular shape), the potential ranges should be chosen to avoid the polymer becoming undoped and thus insulating, at very negative potentials and overoxidized at too positive potentials. As can be seen, the curves of these composite films have nearly rectangular shape, which is typical of the pure capacitive behaviour of the tested object [36]-[40].

The electrochemical characteristics of obtained PEDOT/CNT-PABS/dopant films were study in the same working conditions (see Figure 5 and Figure 6). However, the current of film obtained by potentiodynamic method in presence of dopant is nearly 2 times more than of the film gained in absence of dopant. Analyzing in

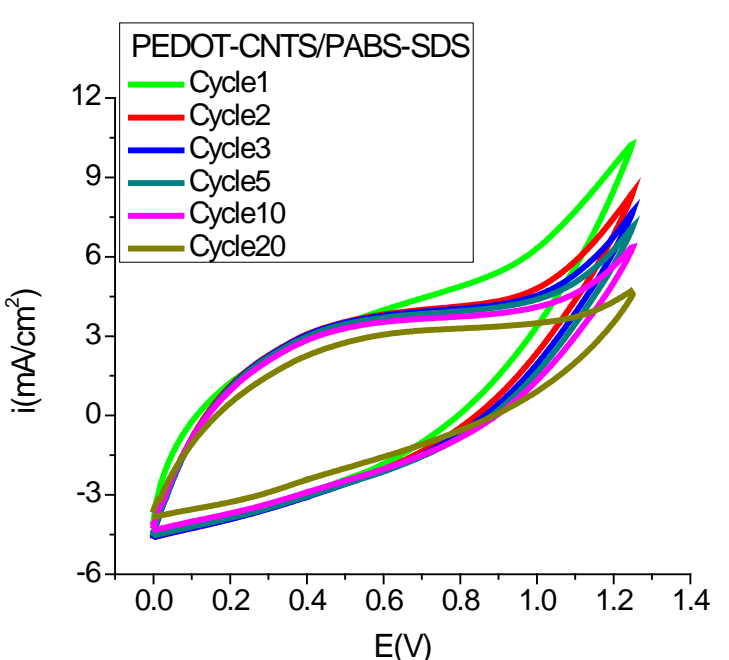

(a)

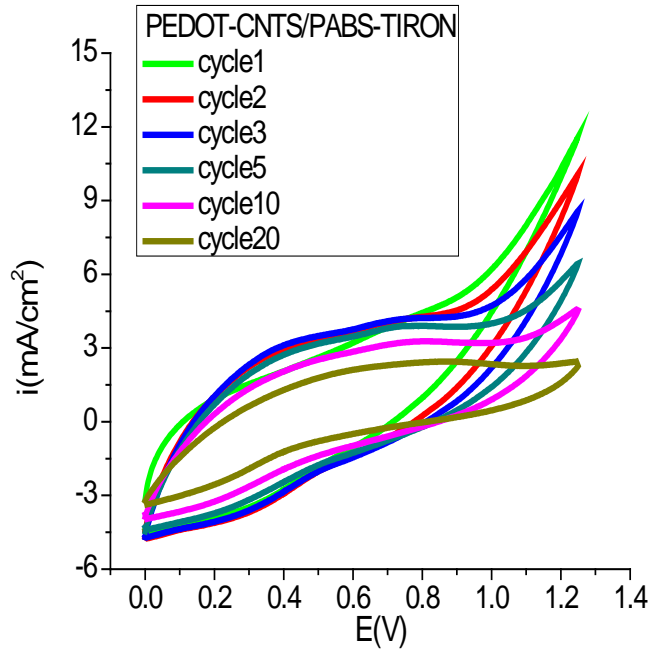

(b)

Figure 5. Cyclic voltammograms of PEDOT/SWCNTs-PABS/SDS and PEDOT/SWCNTs-PABS/tiron film in cycling solution (monomer free) of $0.1 \mathrm{M} \mathrm{LiClO}_{4}$.

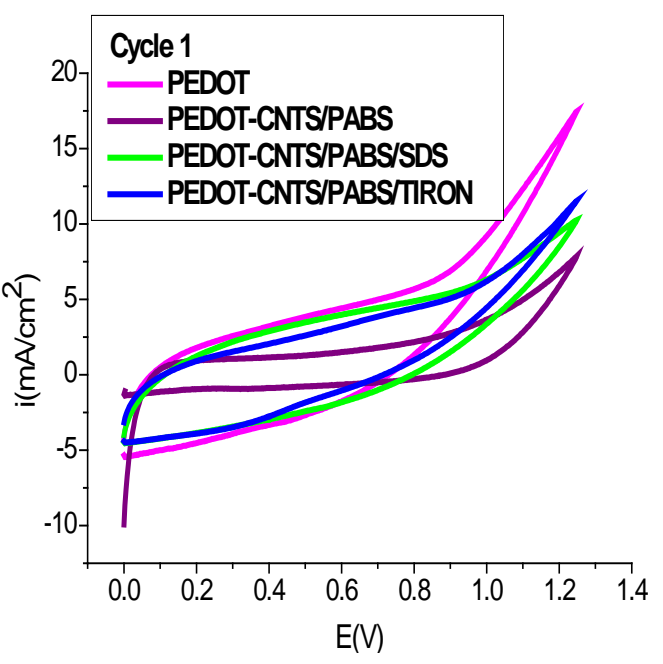

(a)

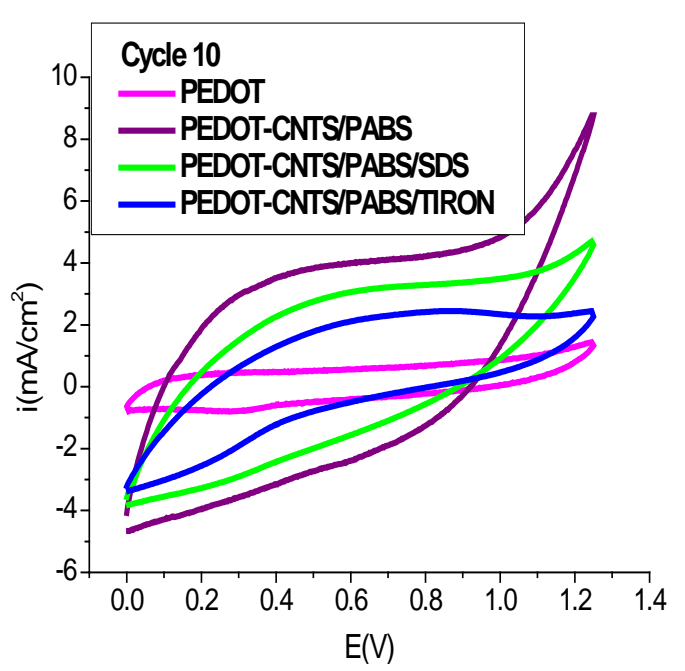

(b)

Figure 6. Comparative cyclic voltammograms of PEDOT/SWCNTs-PABS/dopant films in cycling solution (monomer free) of $0.1 \mathrm{M} \mathrm{LiClO}_{4}, 1^{\text {st }}$ Cycle (a) and $20^{\text {th }}$ Cycle (b). 
comparison the obtained results it can be observed that, in all the cases the PEDOT/CNT-polyaminobenzene sulfonic acid/dopant composite film reveals current much higher than PEDOT film.

The comparison of repetitive cyclic voltammograms between the behaviour of the presented types of electrode shows some differences. By comparing the cyclic voltammograms for PEDOT/PT, PEDOT/CNTs-PABS/ Pt and PEDOT/CNTs-PABS/dopant/Pt films it can be seen that the shape of voltammograms is similar, but the composites presents higher currents than the pure polymeric ones, which can be translated into larger capacitance of the composites. The explanation of this is that the PEDOT chains becoming neutral and the negative charge of immobile functionalized FCNTSF being balanced by the cations with small size from the supporting electrolyte solution, these large CNT anions are immobile and hence expert a permanent electrostatic repulsion to the electron on the polymer chain. The shape of the cyclic voltammograms curve in all the cases is close to rectangular (see Figures 4-6). The best electrochemical behavior is presented by PEDOT/CNTs-PABS/dopant/Pt.

The surface morphology, formation mechanism and electrochemical nature of PEDOT-FSWCNTs films were investigated using scanning electron microscopy (SEM), cyclic voltammetry (CV) and alternating current (AC) impedance spectroscopy (EIS). Cyclic voltammetry and electrochemical impedance spectroscopy revealed that the PEDOT-SWCNTs/PABS electrode had higher electrocatalytic activity for the redox reaction and a smaller charge transfer resistance than the PEDOT electrodes.

Further, the composite films were studied by EIS at open circuit potential, in an aqueous solution of $0.1 \mathrm{M}$ $\mathrm{LiClO}_{4}$ at $25^{\circ} \mathrm{C}$. The resulting Nyquist plots and Bode plots for PEDOT/SWCNTs-PABS and PEDOT/SWCNTsPABS/dopant systems are shown in Figure 7 and Figure 8. The impedance plot is composed of a semicircle

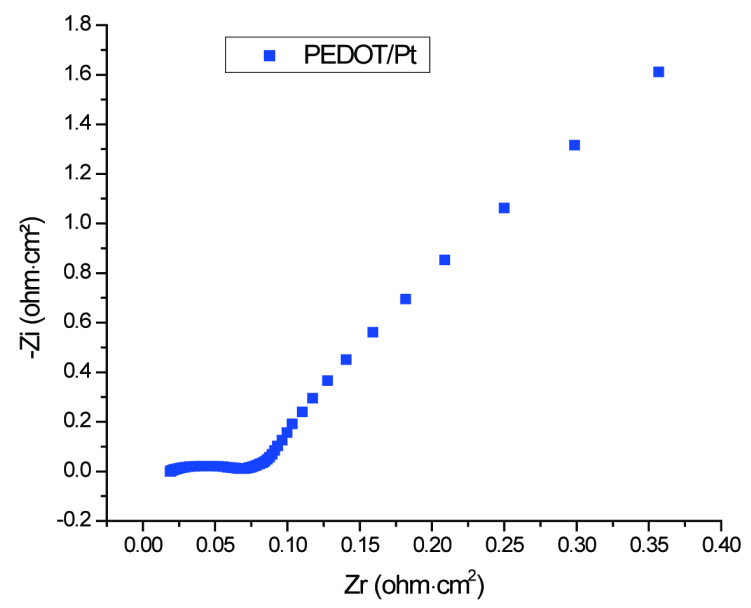

(a)

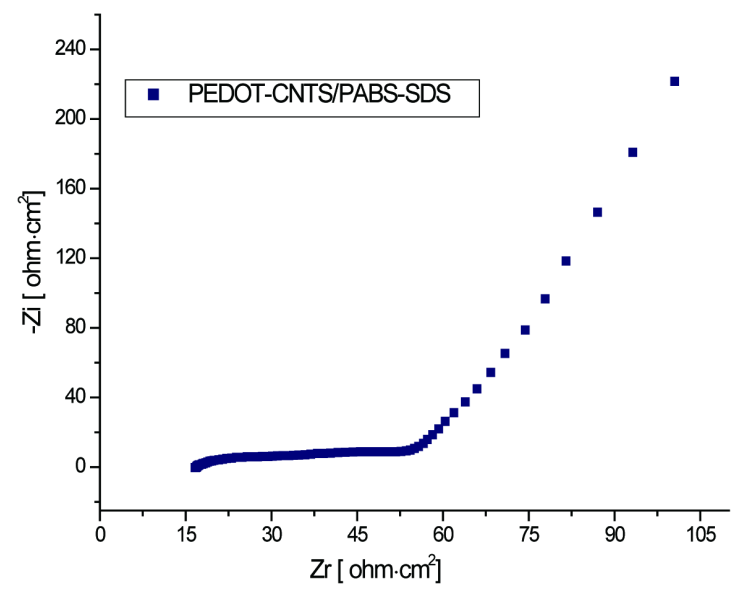

(c)

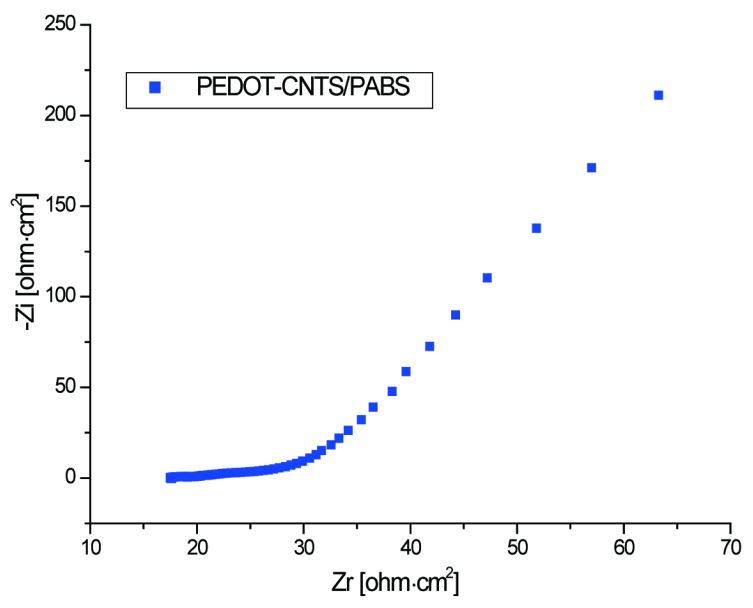

(b)

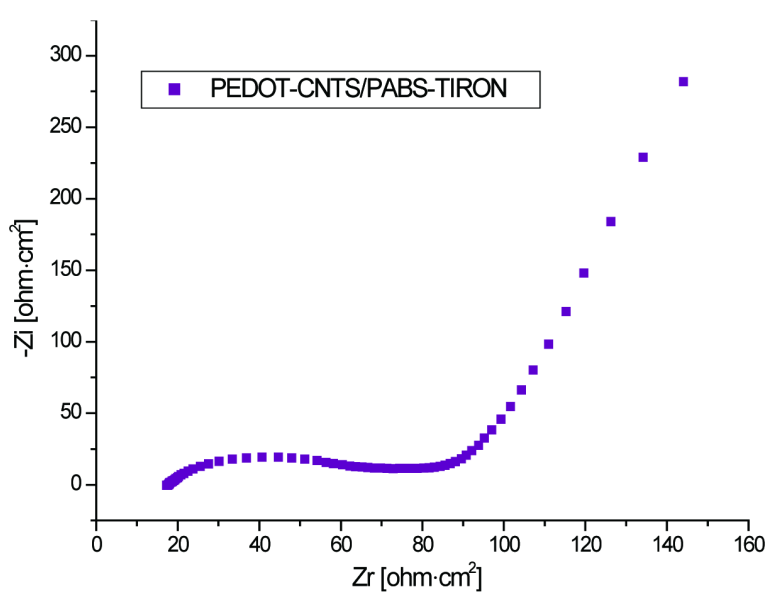

(d)

Figure 7. The Nyquist diagrams for modified electrodes. (a) PEDOT/Pt; (b) PEDOT/SWCNTs-PABS/Pt; (c) PEDOT/SWCNTs$\mathrm{PABS} / \mathrm{SDS} / \mathrm{Pt}$ and (d) PEDOT/SWCNTs-PABS/tiron/Pt at open circuit potential in an aqueous solution of $0.1 \mathrm{M} \mathrm{LiClO}_{4}$. 
at high frequencies and a capacitive slope at low and middle frequencies (see Figure 7 and Figure 8). The semicircle appeared at high frequencies is considered to owe to the charge transfer resistance, which originates from the interface structure between the porous electrode surface and the electrolyte [36]-[39]. At low frequencies, the impedance plot becomes a near vertical line. The Nyquist plots for PEDOT, PEDOT/SWCNTs-PABS and PEDOT/ = SWCNTs-PABS/dopant composite films are featured by a vertical trend at low frequencies, indicating a capacitive behaviour according to the equivalent circuit theory [37]-[40]. Bode diagrams point out also the capacitive behaviour in concordance with Nyquist plots (see in comparison Figures 7(a)-(d) and Figures $8(a)-(d))$.

The capacitances of the electrode materials were calculated, according to the equation:

$$
C=-1 /\left(2 \pi f Z_{i m}\right) \text {. }
$$

( $f$ = frequency; $Z_{\text {im }}=$ imaginary impedance), from the slope of the linear correlation between the imaginary impedance and the reciprocal of the frequency at low frequencies.

From these Figures 7-9 and Table 1, one can observe higher capacitance the one order of magnitude value for PEDOT/FSWCNTs and dopant film in respect with PEDOT pure polymeric films. The embedded FSWCNTs that provide interconnected pathways for electrons through the FSWCNTs and ions through the pore network or the direct interaction between the delocalised electrons on polymer chains and the FSWCNTs contribute to the higher capacitance of the composite films. We can conclude that the capacitance of PEDOT/ FSWCNTs is larger than that of the pure polymeric PEDOT films because the mesoporous structure of FSWCNTs makes the dopping ions center into/eject from PEDOT/FSWCNTs composite films more easily. The combined resistance

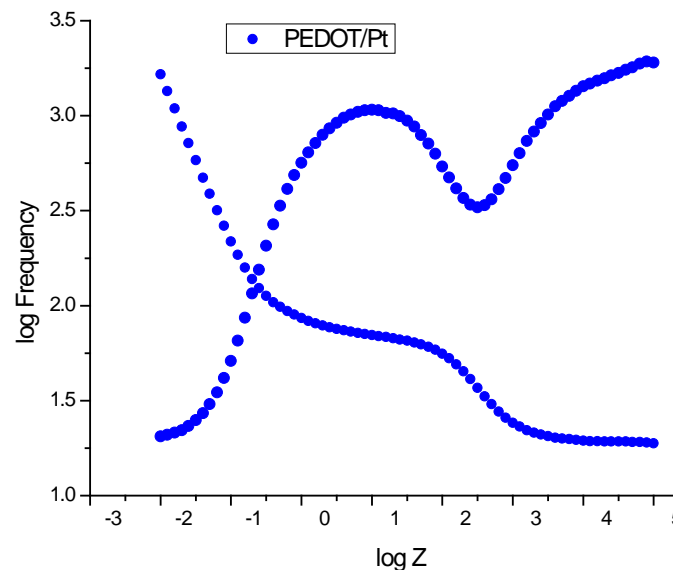

(a)

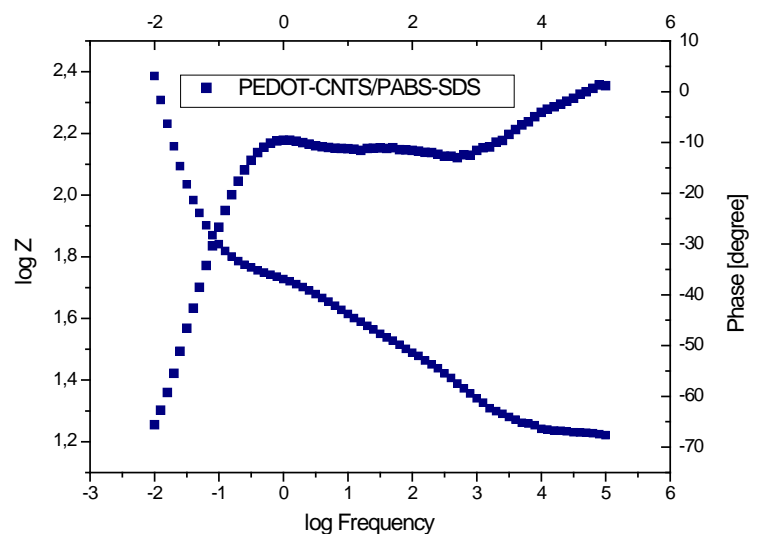

(c)

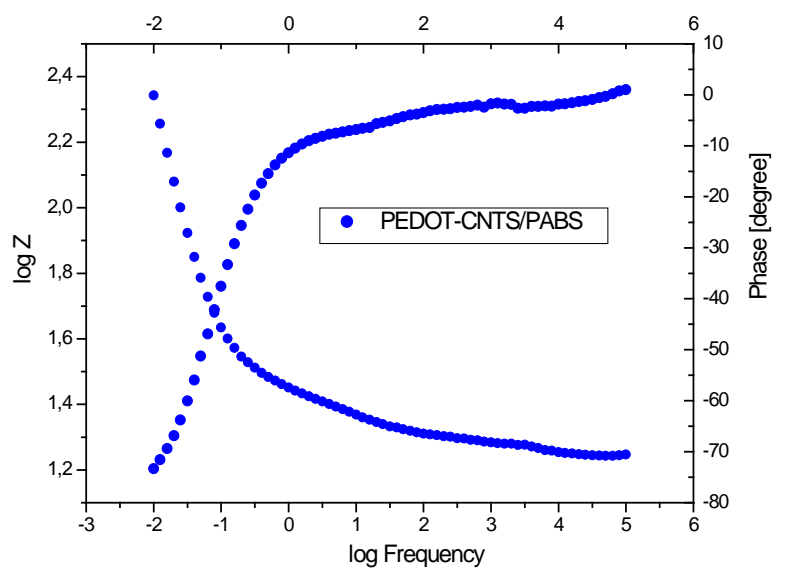

(b)

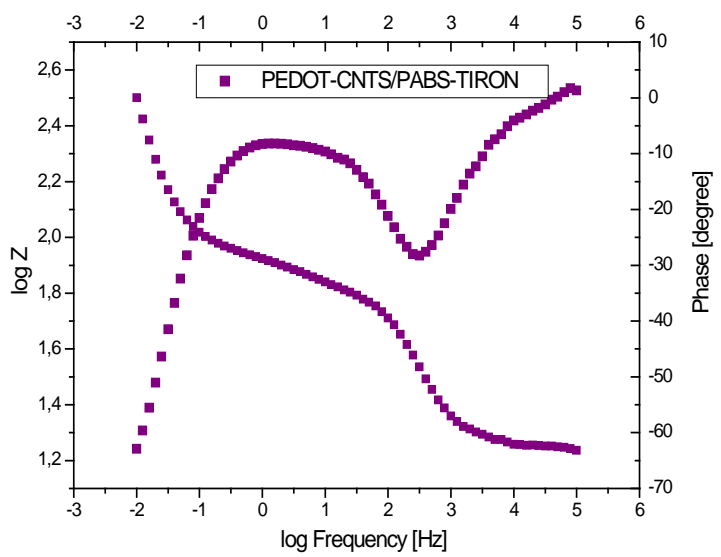

(d)

Figure 8. The Bode diagrams for modified (a) PEDOT/Pt; (b) PEDOT/SWCNTs-PABS/Pt; (c) PEDOT/SWCNTs-PABS/ SDS/Pt and (d) PEDOT/SWCNTs-PABS/tiron/Pt at open circuit potential in an aqueous solution of $0.1 \mathrm{M} \mathrm{LiClO}_{4}$. 


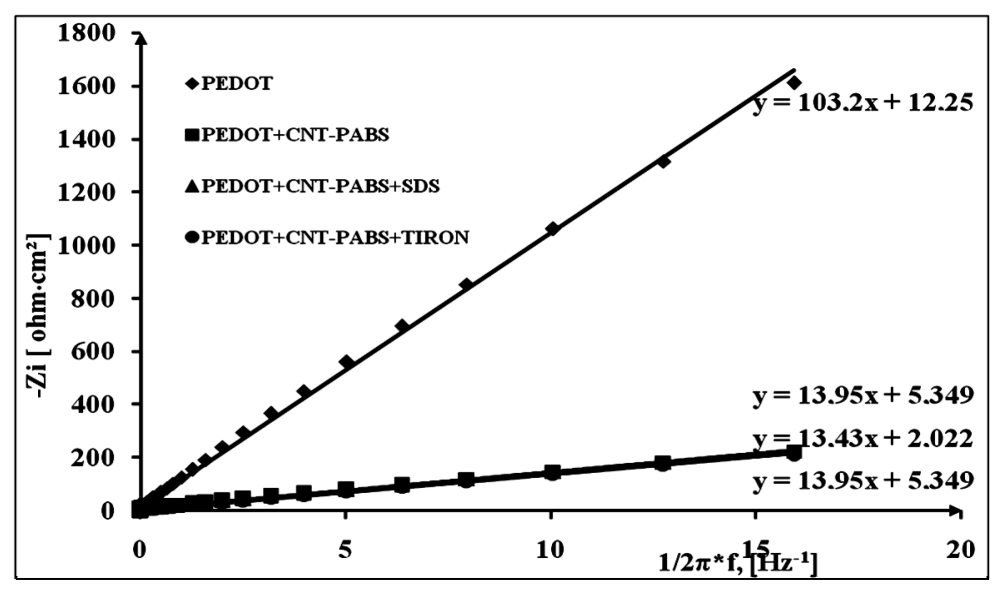

Figure 9. Capacitance evaluation for PEDOT, PEDOT/CNT-PABS and PEDOT/ CNT-PABS/dopant modified electrodes.

Table 1. Real impedance and capacitance values of pure PEDOT film and PEDO/FSWCNTs (polyaminobenzene sulfonic acid) nanocomposite film with different dopants obtained by co-polymerization using the cyclic voltammetry (CV) at 0.01 $\mathrm{Hz}$.

\begin{tabular}{cccc}
\hline Polymeric film & Slope values obtained from graph-Z” $=\mathrm{f}(1 / 2 \pi \mathrm{f})$ & $\mathrm{C}\left[\mathrm{F} / \mathrm{cm}^{2}\right]$ & $\mathrm{Z}_{\mathrm{r}}\left(\Omega \mathrm{cm}^{2}\right)$ at $0.01 \mathrm{~Hz}$ \\
\hline PEDOT & 103 & 0.009 & 357 \\
PEDOT/CNT-PABS & 14 & 0.0714 & 64 \\
PEDOT/CNT-PABS/SDS & 13.5 & 0.0741 & 101 \\
PEDOT/CNT-PABS/tiron & 14 & 0.0714 & 144 \\
\hline
\end{tabular}

of the electrolyte and the film including electronic as well as ionic contributions is indicated by the real impedance at low frequencies where the capacitive behaviour predominates. The values of the real impedance at 0.01 $\mathrm{Hz}$ are given also in Table 1. It can be seen that the PEDOT/FSWCNTs films were significantly lower in resistance than PEDOT films. In comparison with the PEDOT film, it can be observed that PEDOT/FSWCNTs offered much higher overall conductivity. As mentioned before, the real impedance of an electrode material, in general, decreases as the material's porosity increases due to improved ionic accessibility [40]-[49].

Figure 10 shows the SEM images of the PEDOT and composite film. In Figure 10(a) a nodular accumulating structure is evidenced. The size of the nodules ranged a few hundred nanometers in diameter and they aggregate to form gobbets. In Figure 10(b), the effect of dopant on the morphology of PEDOT film can be observed: lamellar structure with almost vertical orientation to the substrate. It is evident that dopant changes the morphology of PEDOT film into a more porous structure with higher interface area. This is in agreement with the SEM results presented below that illustrated a smaller porosity in the PEDOT film than in the case of the composite film (see Figure 10(c)). The SEM images showed that the nanocomposite films, PEDOT/CNT-PABS were more porous than PEDOT films (see Figure 10(c)).

Fourier transform infrared (FT-IR see Figure 11) spectra were carried with a Bruker optics spectrometer at room temperature. All spectra in this paper were obtained at a resolution $4 \mathrm{~cm}^{-1}$ in the region $4000-500 \mathrm{~cm}^{-1}$. FT-IR spectrometer is a powerful instrument that can be used to determine type of bonding for to obtain a new composite. The characteristic bands in the FT-IR spectrum for PEDOT and nanocomposite are the following: a very weak and a medium band at $3000-4000 \mathrm{~cm}^{-1}$ is assigned to the $\mathrm{C}-\mathrm{H}$ and $\mathrm{OH}$ stretching modes; vibration at 1551, 1482, 1353 and $931 \mathrm{~cm}^{-1}$ for PEDOT + nanocompozit and 1521, 1416, 1201 and $904 \mathrm{~cm}^{-1}$ for PEDOT are attributed to the stretching modes of $\mathrm{C}=\mathrm{C}, \mathrm{C}-\mathrm{C}$, and $\mathrm{C}-\mathrm{S}$ in the thiophene ring [50]-[53]. The bands at 1212 and $1056 \mathrm{~cm}^{-1}$ are assigned to the stretching modes of the ethylenedioxy (alkylenedioxy) group and the band around 1039 and $916 \mathrm{~cm}^{-1}$ is due to the ethylenedioxy ring deformation mode. The spectrum shows several bands of which the band at $834 \mathrm{~cm}^{-1}$ for nanocompozit and $813 \mathrm{~cm}^{-1}$ for PEDOT is assigned to the symmetric C-S-C 


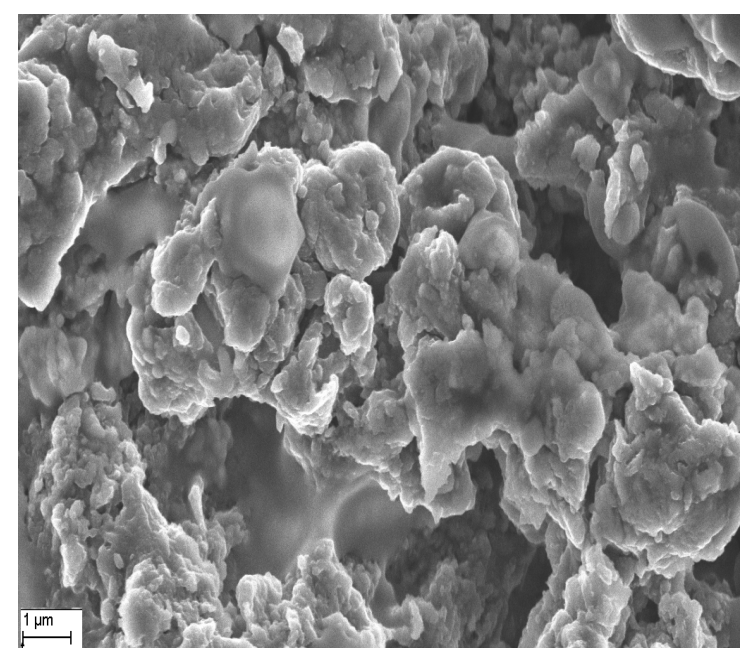

(a)

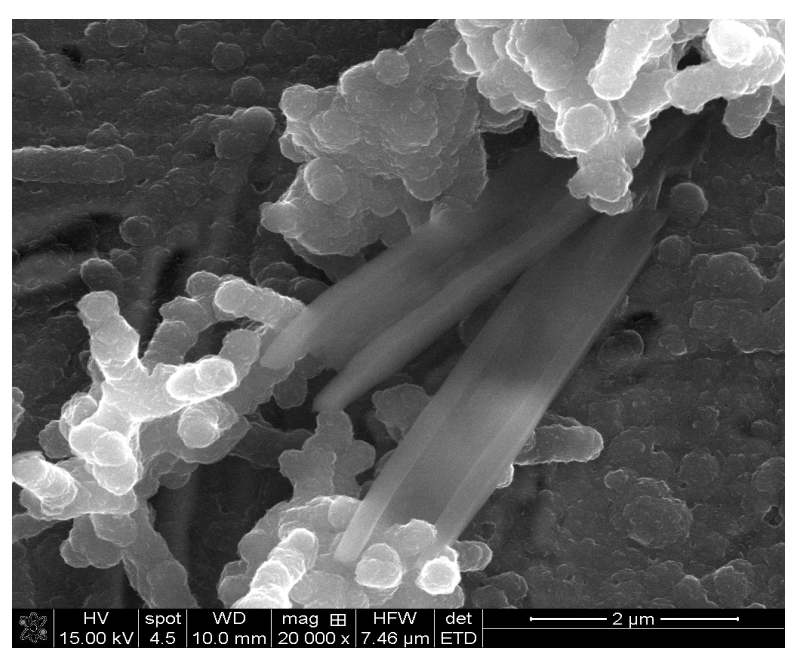

(b)

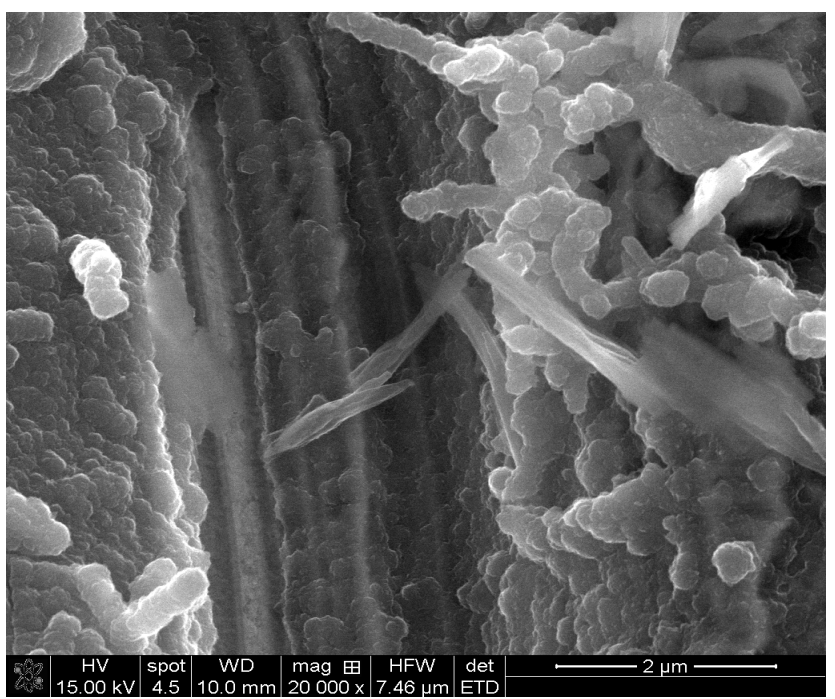

(c)

Figure 10. SEM images of the film surface of (a) PEDOT; (b) PEDOT/SDS and (c) PEDOT/CNT-PABS doped film formation by cyclic voltammetry ( 0 to $1250 \mathrm{mV}$ at a scan rate of $10 \mathrm{mV} / \mathrm{s}$ ).

deformation. The band at $1054 \mathrm{~cm}^{-1}$ (nanocompozit) and $1418 \mathrm{~cm}^{-1}$ (PEDOT) is assigned to the symmetric C-O-C ether bond. A difference that can be observed is the intensity ratio of bands the spectrum (1500 - 600 $\mathrm{cm}^{-1}$ ) of nanocompozit film than PEDOT band, exhibits a clear difference in intensity [54]-[57]. This may suggest that the dopant promotes and stabilizes the structure of the film (nanocomposite).

\section{Conclusions}

Nanocomposite films type PEDOT/FSWCNTs-polyaminobenzene sulfonic acid with different dopants was synthesized by cyclic voltammetry technique from a synthesis solution.

The electrochemical activity of PEDOT/FSWCNTs/dopant/Pt modified electrode in $0.1 \mathrm{M} \mathrm{LiClO}_{4}$ cycling solution is much higher than that of PEDOT/Pt modified electrode in the same cycling solution. Electrochemically synthesiszed composite film of conducting polymer PEDOT and FSWCNTs have in common a porous structure at micro- and nano-meter scales.

Cyclic voltammetry (CV), electrochemical impedance spectroscopy (EIS) and FT-IR spectroscopy demonstrated that these composite films had similar electrochemical response rates to pure polymeric films but a lower resistance and much improved mechanical integrity. 

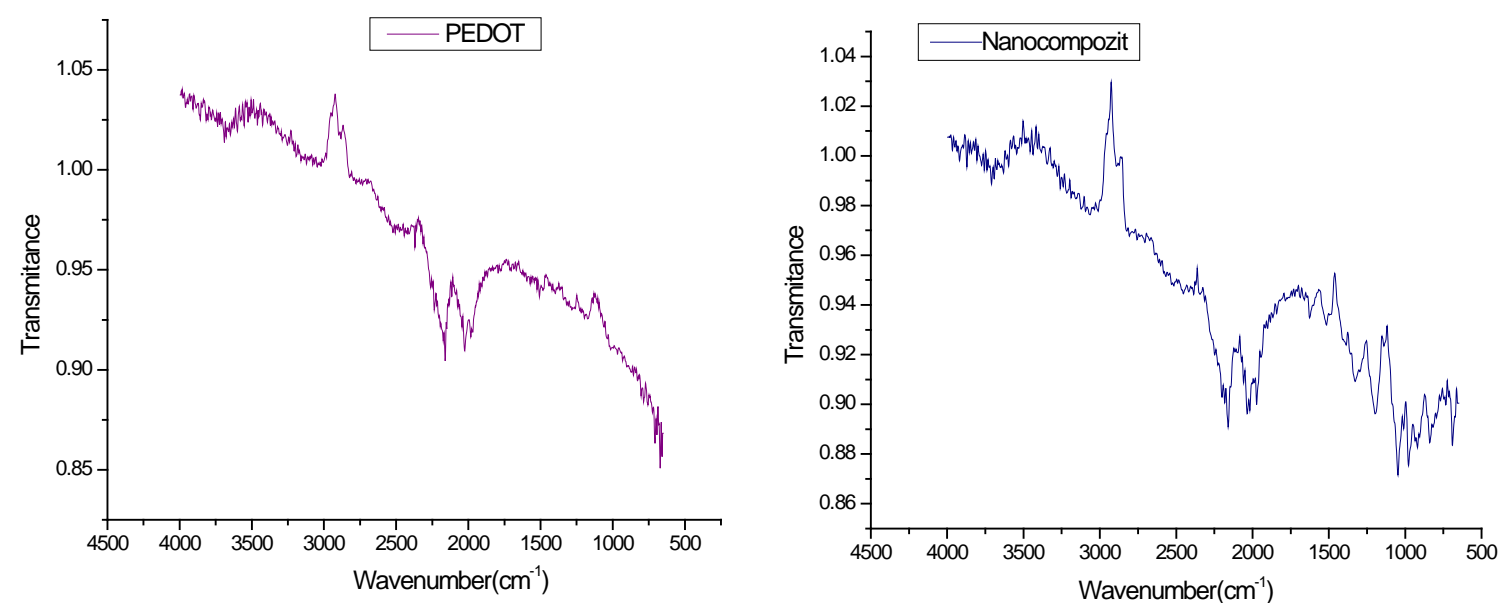

Figure 11. FT-IR spectra of PEDOT and nanocompozit.

The best electrochemical behavior is presented by PEDOT/CNTs-PABS/dopant/Pt.

Nearly rectangular shaped cyclic voltammograms are obtained for all composite films suggesting that the charge and the discharge reversibly occur at the electrode/electrolyte interface.

The Nyquist plots for both PEDOT and composite films PEDOT/FSWCNTs are featured by a vertical trend at low frequencies, indicating a capacitive behaviour according to the equivalent circuit theory.

The PEDOT/FSWCNTs-polyaminobenzene sulfonic acid composite films have high specific capacitance, very quick charging/discharging ability and very low charge transfer resistance.

The SEM micrograph of the composite shows a porous morphology that wrapped on the surface of FSWCNTs.

The PEDOT/FSWCNTs composite was a very promising electrode material for application in supercapacitor.

\section{Acknowledgements}

Financial support from PN-II-ID-PCE-2008-2 contract number 596, code ID_716 (The National University Research Council) is gratefully acknowledged.

\section{References}

[1] Hung, S., Wen, T. and Gopalan, A. (2002) Application of Statistical Design Strategies to Optimize the Conductivity of Electrosynthesized Polypyrrole. Materials Letters, 55, 165-170. http://dx.doi.org/10.1016/S0167-577X(01)00640-1

[2] Morvant, M.C. and Reynolds, J.R. (1998) In Situ Conductivity Studies of Poly(3,4-ethylenedioxythiophene). Synthetic Metals, 92, 57-61. http://dx.doi.org/10.1016/S0379-6779(98)80023-4

[3] Gupta, V. and Miura, N. (2006) High Performance Electrochemical Supercapacitor from Electrochemically Synthesized Nanostructured Polyaniline. Materials Letters, 60, 1466-1469. http://dx.doi.org/10.1016/j.matlet.2005.11.047

[4] Lota, K., Khomenko, V. and Frackowiak, E. (2004) Capacitance Properties of Poly(3,4-ethylenedioxythiophene)/Carbon Nanotubes Composites. Journal of Physics and Chemistry of Solids, 65, 295-301. http://dx.doi.org/10.1016/j.jpcs.2003.10.051

[5] Ajayan, P.M., Stephan, O., Colliex, C. and Trauth, D. (1994) Aligned Carbon Nanotube Arrays Formed by Cutting a Polymer Resin-Nanotube Composite. Science, 265, 1212-1214. http://dx.doi.org/10.1126/science.265.5176.1212

[6] Dai, L. and Mau, A.W.H. (2001) Controlled Synthesis and Modification of Carbon Nanotubes and C 60 : Carbon Nanostructures for Advanced Polymeric Composite Materials. Advanced Materials, 13, 899-913. http://dx.doi.org/10.1002/1521-4095(200107)13:12/13<899::AID-ADMA899>3.0.CO;2-G

[7] Baughman, R.H., Zakhidov, A.A. and Heer, W.A. (2002) Carbon Nanotubes-The Route toward Applications. Science, 297, 787-792. http://dx.doi.org/10.1126/science.1060928

[8] Liao, Y.Z., Zhang, C., Zhang, Y., Strong, V., Kalantar-zadeh, K., Hoek, E., Wang, K. and Kaner, R. (2011) Carbon Nanotube/Polyaniline Composite Nanofibers: Facile Synthesis and Chemosensors. Nano Letters, 11, 954-959. http://dx.doi.org/10.1021/nl103322b

[9] Dai, L. (1999) Advanced Syntheses and Microfabrications of Conjugated Polymers, C60-Containing Polymers and Carbon Nanotubes for Optoelectronic Applications. Polymers for Advanced Technologies, 10, 357-420. 
http://dx.doi.org/10.1002/(SICI)1099-1581(199907)10:7<357::AID-PAT886>3.0.CO;2-9

[10] Chen, G.Z., Shaffer, M.S.P., Coleby, D., Dioxan, G., Fray, D.J. and Windle, A.H. (2000) Carbon Nanotube and Polypyrrole Composites: Coating and Doping. Advanced Materials, 12, 522-526. http://dx.doi.org/10.1002/(SICI)1521-4095(200004)12:7<522::AID-ADMA522>3.0.CO;2-S

[11] Saito, Y., Uemura, S. and Hamaguchi, K. (1998) Cathode Ray Tube Lighting Elements with Carbon Nanotube Field Emitters. Japanese Journal of Applied Physics, 37, L346. http://dx.doi.org/10.1143/JJAP.37.L346

[12] Liao, Y., Zhang, C., Wang, X., Li, X.G., Ippolito, S.J., Kalantar-zadeh, K. and Kaner, R.B. (2011) Carrier Mobility of Single-Walled Carbon Nanotube-Reinforced Polyaniline Nanofibers. The Journal of Physical Chemistry C, 115, 16187-16192. http://dx.doi.org/10.1021/jp2053585

[13] Prună, A., Branzoi, V. and Branzoi, F. (2011) Ordered Arrays of Copper Nanowires Enveloped in Polyaniline Nanotubes. Journal Applied Electrochemistry, 41, 77-81. http://dx.doi.org/10.1007/s10800-010-0209-4

[14] Shirakwa, H. (2001) The Discovery of Polyacetylene Film: The Dawning of an Era of Conducting Polymers (Nobel Lecture), Angew. Angewandte Chemie International Edition, 40, 2574-2580. http://dx.doi.org/10.1002/1521-3773(20010716)40:14<2574::AID-ANIE2574>3.0.CO;2-N

[15] Crispin, X., Jakobsson, F.L.E., Crispin, A., Grim, P.C.M., Andersson, P., Volodin, A., van Haesendonck, C., Van der Auweraer, M., Salaneck, W.R. and Berggren, M. (2006) The Origin of the High Conductivity of Poly (3,4-ethylenedioxythiophene)-poly(styrenesulfonate) (PEDOT-PSS) Plastic Electrodes. Chemistry of Materials, 18, 4354-4360. http://dx.doi.org/10.1021/cm061032+

[16] Breiby, D.W., Samuelsen, L.B. and Groenendaal, B. (2003) Smectic Structures in Electrochemically Prepared Poly (3,4-ethylenedioxythiophene) Films. Journal of Polymer Science Part B: Polymer Physics, 41, 945-952. http://dx.doi.org/10.1002/polb.10412

[17] Luo, S.C., Mohamed, A.E., Tansil, N.C., Yu, H.H., Gao, S. and Ying, J.Y. (2008) Poly(3,4-ethylenedioxythiophene) (PEDOT) Nanobiointerfaces: Thin, Ultrasmooth, and Functionalized PEDOT Films with in Vitro and in Vivo Biocompatibility. Langmuir, 24, 8071-8077. http://dx.doi.org/10.1021/la800333g

[18] Groenendaal, B.L., Jonas, F., Freitag, D., Pielartzik, H. and Reynolds, J.R. (2000) Poly(3,4-ethylenedioxythiophene) and Its Derivatives: Past, Present, and Future. Advanced Materials, 12, 481-494. http://dx.doi.org/10.1002/(SICI)1521-4095(200004)12:7<481::AID-ADMA481>3.0.CO;2-C

[19] Breiby, D.W., Samuelsen, L.B., Groenendaal, B. and Struth, B. (2003) Smectic Structures in Electrochemically Prepared Poly(3,4-ethylenedioxythiophene) Films. Journal of Polymer Science Part B: Polymer Physics, 41, 945-952. http://dx.doi.org/10.1002/polb.10412

[20] Winther-Jensen, B. and West, K. (2006) Stability of Highly Conductive Poly-3,4-ethylene-dioxythiophene. Reactive and Functional Polymers, 66, 479-483. http://dx.doi.org/10.1016/j.reactfunctpolym.2005.08.007

[21] Kros, A., Sommerdijk, N.A.J.M. and Nolte, R.J.M. (2005) Poly(pyrrole) versus Poly(3,4-ethylenedioxythiophene): Implications for Biosensor Applications. Sensors and Actuators B: Chemical, 106, 289-295. http://dx.doi.org/10.1016/j.snb.2004.08.011

[22] Luo, S.C., Mohamed, A.E., Tansil, N.C., Yu, H.H., Gao, S., Kantchev, E.A. and Ying, J.Y. (2008) Poly(3,4-ethylenedioxythiophene) (PEDOT) Nanobiointerfaces: Thin, Ultrasmooth, and Functionalized PEDOT Films with in Vitro and in Vivo Biocompatibility. Langmuir, 24, 8071-8077. http://dx.doi.org/10.1021/la800333g

[23] Branzoi, F. and Branzoi, V. (2014) Enzymatic Electrode Obtained by Immobilizing of Urease into a Nanocomposite Film Based on Conducting Polymers and Different Additives. International Journal of Polymeric Materials and Polymeric Biomaterials, 63, 549-557.

[24] Tanguy, J., Slama, M., Hoclet, M. and Baudouin, J.L. (1989) Impedance Measurements on Different Conducting Polymers. Synthetic Metals, 28, 145-150. http://dx.doi.org/10.1016/0379-6779(89)90512-2

[25] Sivakumar, R. and Saraswathi, R. (2003) Redox Properties of Poly(N-methylaniline). Synthetic Metals, 138, $381-390$. http://dx.doi.org/10.1016/S0379-6779(03)00023-7

[26] Branzoi, F., Branzoi, V. and Musina, A. (2012) Fabrication and Characterisation of Conducting Composite Films Based on Conducting Polymers and Functionalised Carbon Nanotubes. Surface and Interface Analysis, 44, 1076-1081.

[27] Ohsaka, T., Okajima, T. and Oyama, N. (1986) Anion-Exchange Properties of Polymer Films Prepared by Electrochemically Initiated Polymerization of $N, N$-Dialkyl Substituted Aniline Derivatives. Journal of Electroanalytical Chemistry and Interfacial Electrochemistry, 200, 159-178. http://dx.doi.org/10.1016/0022-0728(86)90053-7

[28] Otero, T.F. and De Laretta, E. (1988) Electrochemical Control of the Morphology, Adherence, Appearance and Growth of Polypyrrole Films. Synthetic Metals, 26, 79-88. http://dx.doi.org/10.1016/0379-6779(88)90337-2

[29] Du, X. and Wang, Z. (2003) Effects of Polymerization Potential on the Properties of Electrosynthesized PEDOT Films. 
Electrochimica Acta, 48, 1713-1717. http://dx.doi.org/10.1016/S0013-4686(03)00143-9

[30] Peng, C., Jin, J. and Chen, G.Z. (2007) A Comparative Study on Electrochemical Co-Deposition and Capacitance of Composite Films of Conducting Polymers and Carbon Nanotubes. Electrochimica Acta, 53, 525-537. http://dx.doi.org/10.1016/j.electacta.2007.07.004

[31] Hong, J.-I., Yeo, I.-H. and Paik, W.-K. (2001) Conducting Polymer with Metal Oxide for Electrochemical Capacitor: Poly(3,4-ethylenedioxythiophene) $\mathrm{RuO}_{\mathrm{x}}$ Electrode. Journal of the Electrochemical Society, 148, A156-A163. http://dx.doi.org/10.1149/1.1342166

[32] Du, X. and Wang, Z. (2003) Effects of Polymerization Potential on the Properties of Electrosynthesized PEDOT Films. Electrochimica Acta, 48, 1713-1717. http://dx.doi.org/10.1016/S0013-4686(03)00143-9

[33] Li, L., Loveday, D.C., Mudigonda, D.S.K. and Ferraris, J.P. (2002) Effect of Electrolytes on Performance of Electrochemical Capacitors Based on Poly[3-(3,4-difluorophenyl)thiophene]. Journal of the Electrochemical Society, 149, A1201-A1207. http://dx.doi.org/10.1149/1.1498840

[34] Branzoi, V., Prună, A. and Branzoi, F. (2008) Electrosynthesized Doped Polypyrrole Films on Pure Zinc Electrode. Molecular Crystal and Liquid Crystals, 485, 853-861. http://dx.doi.org/10.1080/15421400801922486

[35] Branzoi, V., Branzoi, F. and Pilan, L. (2009) Characterization of Electrodeposited Polymeric and Composite Modified Electrodes on Cobalt Based Alloy. Materials Chemistry and Physics, 118, 197-203. http://dx.doi.org/10.1016/j.matchemphys.2009.07.020

[36] Ago, H., Petritch, K., Shaffer, M.S.P. and Friend, R.H. (1999) Composites of Carbon Nanotubes and Conjugated Polymers for Photovoltaic Devices. Advanced Materials, 11, 1281-1285. http://dx.doi.org/10.1002/(SICI)1521-4095(199910)11:15<1281::AID-ADMA1281>3.0.CO;2-6

[37] Peng, C., Jin, J. and Chen, G.Z. (2007) A Comparative Study on Electrochemical Co-Deposition and Capacitance of Composite Films of Conducting Polymers and Carbon Nanotubes. Electrochimica Acta, 53, 525-537. http://dx.doi.org/10.1016/j.electacta.2007.07.004

[38] Wang, J., Dai, J. and Yarlagadda, T. (2005) Carbon Nanotube-Conducting-Polymer Composite Nanowires. Langmuir, 21, 9-12. http://dx.doi.org/10.1021/la0475977

[39] Tsai, C., Li, S.C. and Liao, S.W. (2006) Electrodeposition of Polypyrrole-Multiwalled Carbon Nanotube-Glucose Oxidase Nanobiocomposite Film for the Detection of Glucose. Biosensors and Bioelectronics, 22, 495-500. http://dx.doi.org/10.1016/j.bios.2006.06.009

[40] Chen, J., Hamon, M.A., Hu, H., Chen, Y., Rao, A.M., Eklund, P.C. and Haddon, R.C. (1998) Solution Properties of Single-Walled Carbon Nanotubes. Science, 282, 95-98. http://dx.doi.org/10.1126/science.282.5386.95

[41] Chen, Y., Haddon, R.C., Fang, S., Rao, A.M., Eklund, P.C., Lee, W.H., Dickey, E.C., Grulke, E.A., Pendergrass, A. and Smalley, R.E. (1998) Chemical Attachment of Organic Functional Groups to Single-Walled Carbon Nanotube Material. Journal of Materials Research, 13, 2423-2431. http://dx.doi.org/10.1557/JMR.1998.0337

[42] Holzinger, M., Vostrowsky, O., Hirsch, A., Hennrich, F., Kappes, M., Weiss, R. and Jellen, F. (2001) Sidewall Functionalization of Carbon Nanotubes. Angewandte Chemie International Edition, 40, 4002-4005. http://dx.doi.org/10.1002/1521-3773(20011105)40:21<4002::AID-ANIE4002>3.0.CO;2-8

[43] Dyke, C.A. and Tour, J.M. (2003) Unbundled and Highly Functionalized Carbon Nanotubes from Aqueous Reactions. Nano Letters, 3, 1215-1218. http://dx.doi.org/10.1021/nl034537x

[44] Saini, R.K., Chiang, I.W., Peng, H., Smalley, R.E., Billups, W.E., Hauge, R.H. and Margrave, J.L. (2003) Covalent Sidewall Functionalization of Single Wall Carbon Nanotubes. Journal of the American Chemical Society, 125, 36173621.

[45] Dyke, C.A. and Tour, J.M. (2003) Solvent-Free Functionalization of Carbon Nanotubes. Journal of the American Chemical Society, 125, 1156-1157. http://dx.doi.org/10.1021/ja0289806

[46] Williams, K.A., Veenhuizen, P.T.M., de la Torre, B.G., Eritja, R. and Dekker, C. (2002) Nanotechnology: Carbon Nanotubes with DNA Recognition. Nature, 420, 761. http://dx.doi.org/10.1038/420761a

[47] Niyogi, S., Hamon, M.A., Hu, H., Zhao, B., Bhowmik, P., Sen, R., Itkis, M.E. and Haddon, R.C. (2002) Chemistry of Single-Walled Carbon Nanotubes. Accounts of Chemical Research, 35, 1105-1113. http://dx.doi.org/10.1021/ar010155r

[48] Kamaras, K., Itkis, M.E., Hu, H., Zhao, B. and Haddon, R.C. (2003) Covalent Bond Formation to a Carbon Nanotube Metal. Science, 301, 1501. http://dx.doi.org/10.1126/science.1088083

[49] Chen, J., Rao, A.M., Lyuksyutov, S., Itkis, M.E., Hamon, M.A., Hu, H., Cohn, R.W., Eklund, D.T., Smalley, R. and Haddon, R.C. (2001) Dissolution of Full-Length Single-Walled Carbon Nanotubes. The Journal of Physical Chemistry $B$, 105, 2525-2528. http://dx.doi.org/10.1021/jp002596i

[50] Zhao, B., Hu, H. and Haddon, R.C. (2004) Synthesis and Properties of a Water-Soluble Single-Walled Carbon Nano- 
tube-Poly(m-aminobenzene sulfonic acid) Graft Copolymer. Advanced Functional Materials, 14, 71-76. http://dx.doi.org/10.1002/adfm.200304440

[51] Jurewiez, K., Delpeux, S., Bertagna, V. and Frackowiak, E. (2001) Supercapacitors from Nanotubes/Polypyrrole Composites. Chemical Physics Letters, 347, 36-40. http://dx.doi.org/10.1016/S0009-2614(01)01037-5

[52] Gupta, V. and Miura, N. (2006) Polyaniline/Single-Wall Carbon Nanotube (PANI/SWCNT) Composites for High Performance Supercapacitors. Electrochimica Acta, 52, 1721-1726. http://dx.doi.org/10.1016/j.electacta.2006.01.074

[53] Xiao, Q. and Zhou, X. (2003) The Study of Multiwalled Carbon Nanotube Deposited with Conducting Polymer for Supercapacitor. Electrochimica Acta, 48, 575-580. http://dx.doi.org/10.1016/S0013-4686(02)00727-2

[54] Zeng, J.X., Wei, W.Z., Wu, L., Liu, X.Y., Liu, K. and Li, Y. (2006) Fabrication of Poly(toluidine blue O)/Carbon Nanotube Composite Nanowires and Its Stable Low-Potential Detection of NADH. Journal of Electroanalytical Chemistry, 595, 152-160. http://dx.doi.org/10.1016/j.jelechem.2006.07.014

[55] Ferrer-Anglada, N., Kaempgen, M. and Roth, S. (2006) Transparent and Flexible Carbon Nanotube/Polypyrrole and Carbon Nanotube/Polyaniline pH Sensors. Physica Status Solidi B, 243, 3519-3523. http://dx.doi.org/10.1002/pssb.200669220

[56] Santhosh, P., Manesh, K.M., Lee, K.-P. and Gopalan, A.I. (2006) Enhanced Electrocatalysis for the Reduction of Hydrogen Peroxide at New Multiwall Carbon Nanotube Grafted Polydiphenylamine Modified Electrode. Electroanalysis, 18, 894-903. http://dx.doi.org/10.1002/elan.200503474

[57] Lu, G.W., Li, C., Shen, J.Y., Chen, Z.J. and Shi, G.Q. (2007) Preparation of Highly Conductive Gold—Poly(3,4ethylenedioxythiophene) Nanocables and Their Conversion to Poly(3,4-ethylenedioxythiophene) Nanotubes. The Journal of Physical Chemistry C, 111, 5926-5931. http://dx.doi.org/10.1021/jp070387t 